\title{
Genetics of ulcerative colitis: the come-back of interleukin 10
}

Edouard Louis, Cecile Libioulle, Catherine Reenaers, Jacques Belaiche and Michel Georges

Gut 2009;58;1173-1176

doi:10.1136/gut.2008.169235

Updated information and services can be found at:

http://gut.bmj.com/cgi/content/full/58/9/1173

These include:

References This article cites 37 articles, 11 of which can be accessed free at: http://gut.bmj.com/cgi/content/full/58/9/1173\#BIBL

Email alerting Receive free email alerts when new articles cite this article - sign up in the box at service the top right corner of the article

Topic collections Articles on similar topics can be found in the following collections

Ulcerative colitis (913 articles)

Notes

To order reprints of this article go to:

http://journals.bmj.com/cgi/reprintform

To subscribe to Gut go to:

http:/journals.bmj.com/subscriptions/ 


\section{Genetics of ulcerative colitis: the come-back of interleukin 10}

\section{Edouard Louis, ${ }^{1,2}$ Cecile Libioulle, ${ }^{2}$ Catherine Reenaers, ${ }^{1,2}$ Jacques Belaiche, ${ }^{1}$ Michel Georges ${ }^{2}$}

Crohn's disease and ulcerative colitis are chronic, immune-mediated inflammatory diseases of the gastrointestinal tract, affecting up to $0.4 \%$ of the population in Western countries. ${ }^{1}$ They are considered complex multifactorial polygenic diseases. While dramatic progress has been made in deciphering the genetic architecture of Crohn's disease, ulcerative colitis was somewhat left behind, with virtually no relevant studies published until very recently. Although both disorders are considered to belong to the same spectrum of pathologies, the first gene clearly associated with Crohn's disease (CARD$15)^{23}$ did not seem to predispose to ulcerative colitis in any cohort in which it was tested. This finding highlighted some pathogenic differences between the two diseases, and reminded geneticists working on inflammatory bowel diseases (IBDs) of the more modest contribution of genetics to the predisposition to ulcerative colitis, reflected in a lower ratio of disease concordance between monozygotic and dizygotic twins. ${ }^{4}$ The lower heritability of ulcerative colitis also accounts for the fact that most of the linkage studies performed in the 1990s did not include sufficient ulcerative colitisaffected sib pairs to disclose ulcerative colitis-related loci. With few exceptions, ${ }^{5-7}$ reports of associations with candidate genes have not been confirmed. Recently, major advances in cataloguing common genetic variants in humans combined with the development of highthroughput single nucleotide polymorphism (SNP) genotyping capacity, have made large-scale, genome-wide association studies (GWASs) with hundreds of thousands of common SNPs feasible. These have dramatically increased the list of loci shown to be associated with Crohn's disease, ${ }^{8-13}$ and now also with ulcerative colitis ${ }^{14-17}$ (table 1).

\footnotetext{
${ }^{1}$ Department of Gastroenterology, CHU of Liège, University of Liège, Belgium; ${ }^{2}$ GIGA Research, University of Liège, Belgium

Correspondence to: Dr Edouard Louis, Department of Gastroenterology, CHU of Liège, 4000 Liège, Belgium; Edouard.louis@ulg.ac.be
}

First, a series of loci previously shown to be associated with Crohn's disease were tested for their effect on the predisposition to ulcerative colitis in cohorts of appropriate size. A substantial number were found to be associated with ulcerative colitis, including important immunological players such as $I L 23 R$ or $I L 12 B .{ }^{14}$ In some cases, notably HERC2 and STAT3, the associations seemed even stronger for ulcerative colitis than for Crohn's disease.

A genome scan with non-synonymous SNPs subsequently revealed novel associations specific for ulcerative colitis. ${ }^{15}$ Among these, the strongest association was for two SNPs at the ECM1 locus. Although fine mapping is needed to clearly identify the causative variants, ECM1 itself is a relevant candidate gene for ulcerative colitis, as it is implicated in the interaction between epithelium and basal membrane and strongly activates nuclear factor $\kappa \mathrm{B}(\mathrm{NF}-\kappa \mathrm{B})$ signalling. ${ }^{18}$ The same SNPs were previously shown to be weakly associated with ankylosing spondylitis, thus slowly adding to the fascinating genetic jigsaw of immune-mediated inflammatory disease. ${ }^{19}$ Other strong associations were found for variants within the HLA complex, including HLADQA1, HLADRA, HLADRB5 and $H L A D R B 1$. These confirmed previously reported associations, particularly for HLADRB $1 .{ }^{20}$ Very interestingly, HLA variants predisposing to ulcerative colitis were shown to increase risk for pure colonic Crohn's disease while protecting against pure ileal Crohn's disease, thus reemphasising major genetic differences between ileal and colonic IBDs, as previously noted for CARD15.

Finally, two full GWASs for ulcerative colitis were published very recently. ${ }^{16}{ }^{17}$ In the first European study, 440794 SNPs were first genotyped in 1167 Caucasian patients with ulcerative colitis and 777 healthy controls. ${ }^{16}$ Twenty of the most significant associations were tested for replication in three independent European case-control panels comprising a total of 1855 patients with ulcerative colitis and 3091 controls. In addition to disclosing new SNPs associated with ulcerative colitis in the HLAII-BTNL2 region, this study revealed two important brand new associations The first is with SNPs near the ARPC2 locus. The function of ARPC2 in human is not known. The microbial equivalent of ARP2/3 associates with the protein encoded by the WAS gene (involved in the Wiskot-Aldrich syndrome) which plays a role in the regulation of regulatory $\mathrm{T}$ cells. ${ }^{21}$ The second new association is with SNPs near the $3^{\prime}$ UTR of the IL10 gene at $1 \mathrm{q} 32$. The latter SNPs were the most significantly associated (outside the HLA complex), with $\mathrm{p}$ values reaching $1.35 \times 10^{-12}$ in the combined analysis and an odds ratio of 1.46 (1.31-1.62). The second study from the United States included, overall for the GWAS and two replication cohorts, 2439 patients with ulcerative colitis and 3686 controls all of European ancestry. ${ }^{17}$ This study confirmed association with several SNPs at the IL23R locus on chromosome 1 p31 and with a region spanning BTNL2 to HLA-DQB1 on chromosome 6p21. It also showed new association with loci on chromosomes 1 p36 and 12q15. Important candidate genes at these loci are PLA2GE2, coding for a secretory phospholipase A2, as well as IFNG (interferon gamma, a critical cytokine in the immune response to pathogens) IL22 and IL26 (interleukin 22 and interleukin 26 secreted by TH-17 cells).

The strong association with the IL10 gene found in the European GWAS is arguably one of the most exciting. A fine mapping strategy confirmed the association with the IL10 locus and suggested the possibility of multiple causative variants which, however, remain to be clearly identified.

It has been recognised for a long time that IL10 is a very important anti-inflammatory cytokine in intestinal immune homeostasis, potentially involved in the pathogenesis of IBD. The first convincing evidence for an implication of IL10 in intestinal immune regulation and in the development of enterocolitis came from IL10-/- mice which spontaneously develop enterocolitis. ${ }^{22}$ In this model, the inflammation mainly affects the mucosa along the gastrointestinal tract and is characterised in the colon by enlarged and branched crypts, reduced number of goblet cells, degeneration of superficial epithelial cells and increased expression of major histocompatibility complex (MHC) class II molecules. An important protective role of IL10 was also obtained in alternative models of colitis, including the transfer of $\mathrm{CD}^{+} \mathrm{CD}^{+} 5 \mathrm{RB}^{\text {high }} \mathrm{T}$ cells to 
Table 1 Single nucleotide polymorphisms (SNPs) significantly associated with ulcerative colitis, identified through genome-wide association studies $^{15-17}$ or systematic testing after significant association with Crohn's disease in genome-wide association studies ${ }^{14}$

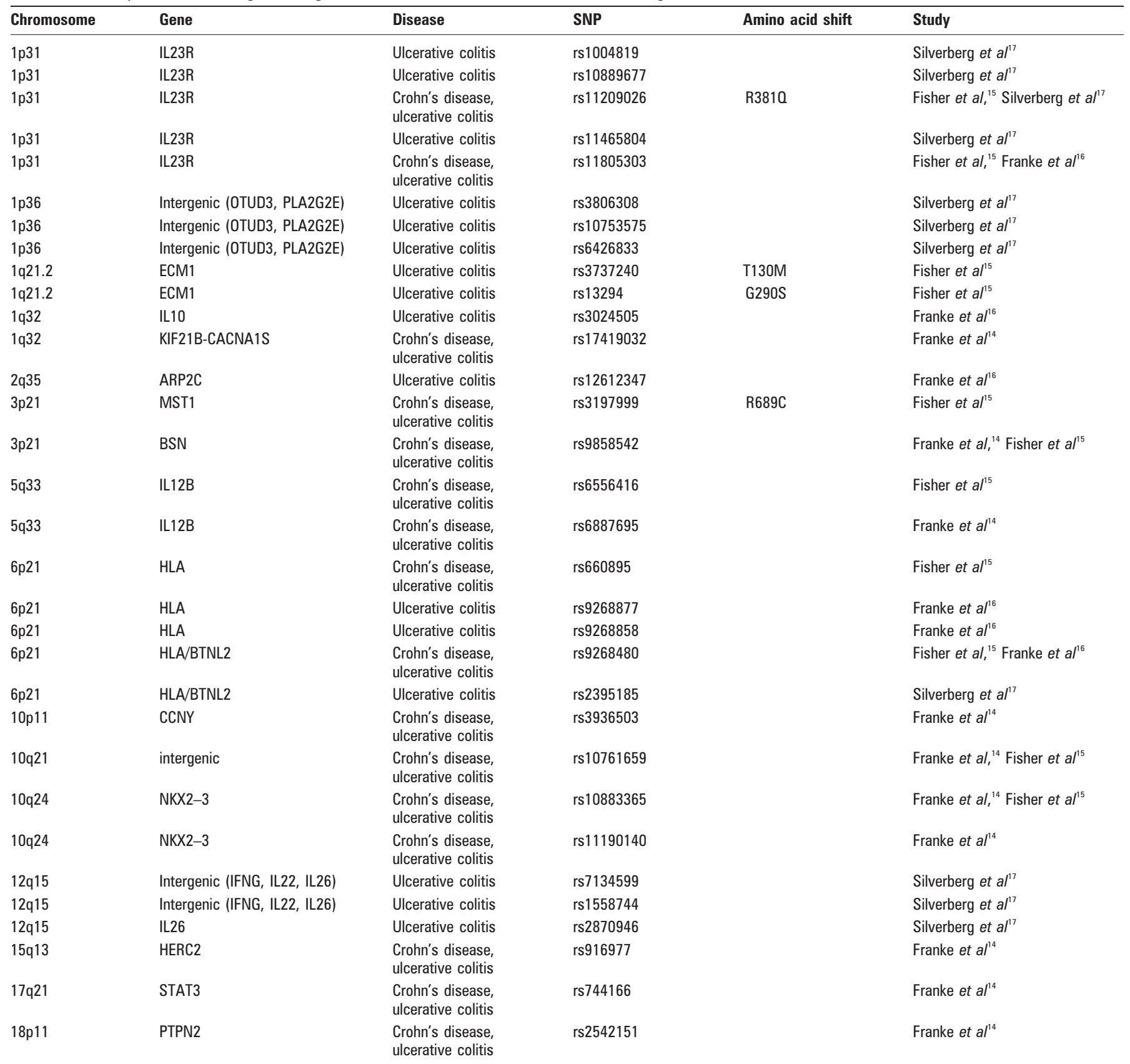

For SNPs in intergenic regions, candidate genes in the vicinity are given in brackets.

immunodeficient mice. In this system, colitis can be prevented or cured by the co-transfer of IL10 producing regulatory T cells. ${ }^{23}$ Production of IL10 by these cells was shown to be essential for the prevention or cure of colitis. During the healing process, IL10-producing regulatory $\mathrm{T}$ cells selectively accumulate within the colonic lamina propria, suggesting compartmentalisation of these regulatory $T$ cells at effector sites. These IL10 defect dependent colitis models do not develop in germ-free mice, highlighting the role of intestinal bacteria in the stimulation of chronic inflammation. ${ }^{24}$ Appropriate production of
IL10 could thus regulate the mucosal immune response to the enteric flora, preventing the development of chronic inflammation. Bacteria-induced chronic inflammation of the colon has also been associated with the development of colonic cancer, mimicking what may happen in ulcerative colitis. Here again, IL10 appeared to play a key role in preventing tumour development. ${ }^{25}$ Besides germs, drugs (such as non-steroidal anti-inflammatory drugs (NSAIDs)) and stress may favour the development of colitis in predisposed subjects. Indeed, in IL10-deficient mice, NSAIDs induced rapid development of colitis with infiltration of macrophages and interferon-gamma-producing $\mathrm{CD}^{+} \mathrm{T}$ cells in the lamina propria, ${ }^{26}$ which persisted after withdrawal of the NSAID. In wild-type mice, NSAIDs had minimal effect on the colon. Also, in vitro production of IL10 by peripheral blood cells under $\beta$-adrenergic stimulation was decreased in ulcerative colitis patients, suggesting a protective role of IL10 against stress-related colitis. ${ }^{27}$ IL10 thus appears to play a key role in many aspects of the regulation of the immune-mediated inflammatory reaction characterising IBDs (fig 1). The mechanism by which IL10 can attenuate or prevent 


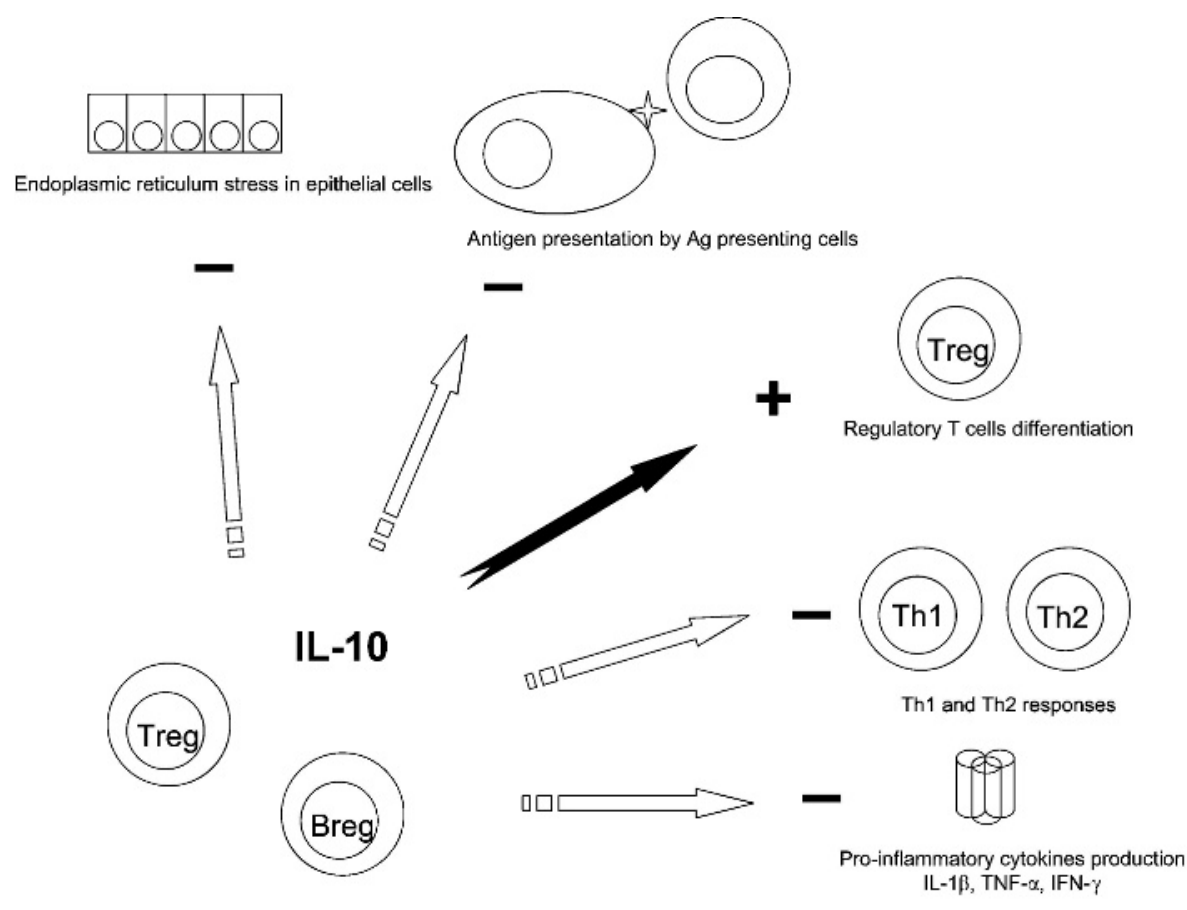

Figure 1 Mechanisms for the prevention of chronic colitis by interleukin 10 (IL10). A whole range of effects of IL10, potentially preventing against the development of chronic colitis has been described. This includes a protective effect against reticulum endoplasmic stress in epithelial cells, inhibition of antigen-presenting cells, inhibition of T helper (Th)1 and Th2 immune responses, inhibition of production of pro-inflammatory cytokines, and the stimulation of differentiation of subsets of regulatory T cells. In the colon, IL10 is mainly produced by T and B regulatory cells.

colitis involves inhibition of pro-inflammatory cytokines and prevention of endoplasmic reticulum stress. In particular, IL10-/ - mice lack transforming growth factor $\beta$ / Smad signalling and fail to inhibit proinflammatory gene expression in intestinal epithelial cells after the colonisation with colitogenic bacteria. ${ }^{28}$ Also, proteomic analysis of functional epithelial cells showed that IL10 can block endoplasmic reticulum stress and chronic inflammation by modulating activating transcription factor (ATF)-6 nuclear recruitment to the grp-78 gene promoter. ${ }^{29}$

The exact nature of the IL10 defect in ulcerative colitis remains to be discovered. Previous studies have not shown a dramatic decrease in IL10 production in the colonic mucosa of ulcerative colitis patients. In contrast, in inflamed mucosa, a very significant increase of IL10 levels was observed. ${ }^{30}{ }^{31}$ Nevertheless, reduced in vitro regulation of IL10 has been shown in inflammatory immune cells of ulcerative colitis patients. ${ }^{32}$ The defect in ulcerative colitis could involve the diminished production by specific cell populations, such as epithelial or regulatory $\mathrm{T}$ cells, an abnormal response to specific stimuli, or the production of an IL10 with diminished affinity for its receptors. One of the main SNPs associated with ulcerative colitis is located very closely to a highly conserved stretch of
DNA containing a putative activating protein-1 (AP-1) binding site. ${ }^{16}$ AP-1 can be activated by lipopolysaccharide in macrophages. IL10 could thus be part of a regulatory response to such stimulation. Two new exonic SNPs were also found by re-sequencing the IL10 gene. ${ }^{16}$ These variants could influence the binding of IL10 to its high-affinity receptor $\mathrm{A}$.

Despite encouraging initial results in treating mild-to-moderate ulcerative colitis with human recombinant IL10,33 enthusiasm for the effectiveness of IL10 in the prevention and treatment of colitis has been tempered by its failure to induce remission or prevent recurrence in Crohn's disease controlled trials. ${ }^{34}{ }^{35}$ Interestingly, the SNPs associated with ulcerative colitis in the recent study by Franke et al were only weakly associated with Crohn's disease, suggesting a more prominent pathogenic role for IL10 in ulcerative colitis than in Crohn's disease. ${ }^{16}$ Whatever the nature of the IL10 defect in ulcerative colitis, the development of IL10-based treatment of ulcerative colitis should now be a priority. Unravelling the precise nature of the underlying defect may guide the choice between alternative treatment options, including systemic injection, topical administration, enhancement of production by probiotics $^{36}$ or even local production of IL10 by genetically modified probiotics. ${ }^{37}$ A systemic administration, as tested mainly in Crohn's disease, would probably be suboptimal to correct a selective defect of production in epithelial cells or mucosal regulatory $T$ cells upon stimulation by luminal bacterial components.

Competing interests: None.

Revised 27 April 2009

Accepted 28 April 2009

Gut 2009;58:1173-1176. doi:10.1136/gut.2008.169235

\section{REFERENCES}

1. Loftus EV. Clinical epidemiology of inflammatory bowel diseases: incidence, prevalence and environmental influences. Gastroenterology 2004;126:1504-17.

2. Hugot JP, Chamaillard M, Zouali $\mathrm{H}$, et al. Association of NOD2 leucine-rich repeat variants with susceptibility to Crohn's disease. Nature 2001;:411:599-603.

3. Ogura Y, Bonen DK, Inohara N, et al. A frameshift mutation in NOD2 associated with susceptibility to Crohn's disease. Nature 2001;411:603-6.

4. Halfvarson J, Bodin L, Tysk C, et al. Inflammatory bowel disease in a Swedish twin cohort: a long-term follow-up of concordance and clinical characteristics. Gastroenterology 2003;124:1767-73.

5. Dideberg V, Kristjansdottir G, Milani L, et al. An insertion-deletion polymorphism in the interferon regulatory factor 5 (IRF5) gene confers risk of inflammatory bowel diseases. Hum $\mathrm{Mol}$ Genet 2007; 16:3008-16.

6. Stokkers PC, Reitsma PH, Tytgat GN, et al. HLA-DR and -DO phenotypes in inflammatory bowel disease: a meta-analysis. Gut 1999;265:2037-48.

7. Annese V, Valvano MR, Palmieri 0, et al. Multidrug resistance 1 gene in inflammatory bowel disease: a meta-analysis. World J Gastroenterol 2006;12:3636-44.

8. Yamazaki K, McGovern D, Ragoussis J, et al. Single nucleotide polymorphisms in TNFSF15 confer susceptibility to Crohn's disease. Hum Mol Genet 2005; 14:3499-506.

9. Duerr RH, Taylor KD, Brant SR, et al. A genome-wide association study identifies IL23R as an inflammatory bowel disease gene. Science 2006;314:1461-3.

10. Hampe J, Franke A, Rosentiel P, et al. A genomewide association scan of nonsynonymous SNPs identifies a susceptibility variant for Crohn disease in ATG16L1. Nat Genet 2007;39:207-11.

11. Parkes M, Barrett JC, Prescott NJ, et al. Sequence variants in the autophagy gene IRGM and multiple other replicating loci contribute to Crohn's disease susceptibility. Nat Genet 2007;39:830-2.

12. Rioux JD, Xavier RJ, Taylor KD, et al. Genome-wide association study identifies new susceptibility loci for Crohn disease and implicates autophagy in disease pathogenesis. Nat Genet 2007;39:596-604.

13. Libioulle C, Louis E, Hansoul S, et al. A novel susceptibility locus for Crohn's disease identified by whole genome association maps to a gene desert on chromosome $5 p 13.1$ and modulates the level of expression of the prostaglandin receptor EP4. Plos Genetics 2007;3:538-43.

14. Franke A, Balschun $\mathrm{T}$, Karlsen $\mathrm{TH}$, et al. Replication of signals from recent studies of Crohn's disease identifies previously unknown disease loci for ulcerative colitis. Nat Genet 2008;40:713-5.

15. Fisher SA, Tremelling M, Anderson CA, et al. Genetic determinants of ulcerative colitis include the ECM1 locus and five loci implicated in Crohn's disease. Nat Genet 2008;40:710-2.

16. Franke A, Balschun $\mathrm{T}$, Karlsen $\mathrm{TH}$, et al. Sequence variants in IL10, ARPC2 and multiple other loci contribute to ulcerative colitis susceptibility. Nat Genet 2008;40:1319-23.

17. Silverberg MS, Cho JH, Rioux JD, et al. Ulcerative colitis-risk loci on chromosomes 1p36 and 12q15 
found by genome-wide association study. Nat Genet 2009;41:216-20.

18. Chan I, Liu L, Hamada T, et al. The molecular basis of lipoid proteinosis: mutations in extracellular matrix protein 1. Exp Dermatol 2007;16:881-90.

19. WTCCC. Genome-wide association study of 14,000 cases of seven common diseases and 3,000 shared controls. Nature 2007:447:661-78.

20. Satsangi J, Welsh KI, Bunce M, et al. Contribution of genes of the major histocompatibility complex to susceptibility and disease phenotype in inflammatory bowel disease. Lancet 1996;346:1212-7.

21. Marangoni F, Trifari S, Scaramuzza S, et al. WASP regulates suppressor activity of human and murine CD4(+)CD25(+)FOXP3(+) natural regulatory T cells. J Exp Med 2007;204:369-80.

22. Kühn R, Löhler J, Rennick D, et al. Interleukin-10deficient mice develop chronic enterocolitis. Cell 1993;75:263-74.

23. Uhlig H, Coombes J, Mottet C, et al. Characterization of Foxp3+CD4+CD25+ and IL-10-secreting CD4+CD25+ cells during cure of colitis. J Immuno/ 2006;177:5852-60.

24. Sellon RK, Tonkonogy S, Schultz M, et al. Resident bacteria are necessary for development of spontaneous colitis and immune system activation in interleuki-10-deficient mice. Infect Immun 1998;66:5224-31.

25. Erdman SE, Rao VP, Poutahidis T, et al. CD4+ CD25+ regulatory lymphocytes require interleukin 10 to interrupt colon carcinogenesis in mice. Cancer Res 2003;63:6042-50

26. Berg DJ, Zhang J, Weinstock JV, et al. Rapid development of colitis in NSAID-treated IL-10-deficient mice. Gastroenterology 2002;123:1527-42.

27. Langhorst J, Cobelens PM, Kavelaars A, et al Stress-related peripheral neuroendocrine-immune interactions in women with ulcerative colitis. Psychoneuroendocrinology 2007;32:1086-96.

28. Ruiz PA, Shkoda A, Kim SC, et al. IL-10 genedeficient mice lack TGF-beta/Smad signalling and fail to inhibit proinflammatory gene expression in intestinal epithelial cells after the colonization with colitogenic enterococcus faecalis. J Immunol 2005:174:2990-9.

29. Shkoda A, Ruiz PA, Daniel H, et al. Interleukin-10 blocked endoplasmic reticulum stress in intestinal epithelial cells: impact on chronic inflammation. Gastroenterology 2007;132:190-207.

30. Louis E, Ribbens C, Godon A, et al. Increased production of stromelysin-1 (MMP-3) and tissue inhibitor of metalloproteinase-1 (TIMP-1) by inflamed mucosa in inflammatory bowel disease. Clin Exp Immunol 2000;120:241-6.

31. Matsuda R, Koide T, Tokoro C et al Ouantitative cytokine mRNA expression profiles in the colonic mucosa of patients with steroid naïve ulcerative colitis during active and quiescent disease. Inflamm Bowel Dis 2009;15:328-34.

32. Schreiber S, Heinig T, Thiele HG, et al. Immunoregulatory role of interleukin 10 in patients with inflammatory bowel disease. Gastroenterology 1995:108:1434-44.

33. Schreiber S, Fedorak R, Wild G, et al. Ulcerative colitis IL-10 cooperative study grp. Safety and tolerance of rHulL-10 treatment in patients with mild/moderate active ulcerative colitis. Gastroenterology 1998;114:A1080-1.

34. Schreiber S, Fedorak RN, Nielsen $\mathrm{OH}$, et al. Safety and efficacy of recombinant human interleukin 10 in chronic active Crohn's disease. Crohn's Disease IL-10 Cooperative Study Group. Gastroenterology 2000:119:1461-72.

35. Colombel JF, Rutgeerts $\mathrm{P}$, Malchow $\mathrm{H}$, et al. Interleukin 10 (Tenovil) in the prevention of postoperative recurrence of Crohn's disease. Gut 2001;49:42-6

36. Sokol H, Pigneur B, Watterlot $L$, et al. Faecalibacterium prausnitzii is an anti-inflammatory commensal bacterium identified by gut microbiota analysis of Crohn disease patients. Proc Natl Acad Sci USA 2008;105:16731-6

37. Steidler L, Hans W, Schotte L, et al. Treatment of murine colitis by Lactococcus lactis secreting interleukin-10. Science 2000;289:1352-5.

\section{Editor's quiz: GI snapshot}

\section{Epigastric pain and elevated pancreatic enzymes}

\section{CLINICAL PRESENTATION}

A 54-year-old man presented with epigastric abdominal pain radiating to the back of several days duration. The pain was continuous and not associated with nausea, vomiting or food intake. On examination he was noted to have slight tenderness over the epigastric region and no organomegaly. Laboratory investigations including liver function tests, complete blood count and urinalysis were normal except for an elevation in the serum amylase (165 IU/1) and lipase (241 IU/1) levels. Abdominal ultrasound was negative for any biliary pathology and the pancreatic parenchyma displayed normal echogenicity. The patient was treated conservatively but failed to improve. A 64-slice CT scan was obtained (fig 1). Upper endoscopy revealed a submucosal bulge $1-2 \mathrm{~cm}$ below the gastrooesophageal junction along the lesser curvature with an intact overlying gastric mucosa. Endoscopic ultrasound further revealed that the mass was arising from the muscularis propria layer of the gastric wall with mixed echogenicity and central hypodensity.

\section{OUESTION}

What is your diagnosis?

See page 1199 for the answer.
Robin Spiller, editor

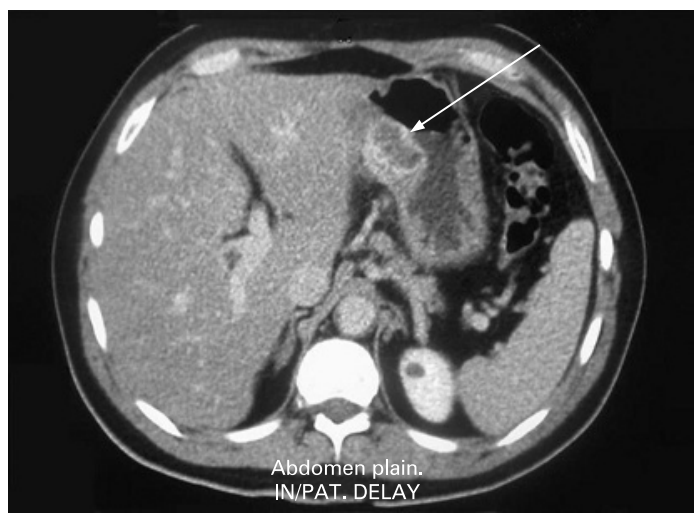

Figure 1 CT scan of the abdomen showing a $4.2 \times 2.3 \mathrm{~cm}$ enhancing soft tissue mass (white arrow) along the lesser curvature of the stomach with a hypodense central area consistent with central necrosis.

\section{Khreiss, ${ }^{1}$ K M Musallam, ${ }^{1}$ A Soweid, ${ }^{2}$ G Zaatari, ${ }^{3}$ A S Yakan, F R Jamali ${ }^{1}$}

${ }^{1}$ Department of Surgery, American University of Beirut Medical Center, Beirut, Lebanon; ${ }^{2}$ Department of Medicine, American University of Beirut Medical Center, Beirut, Lebanon; ${ }^{3}$ Department of Pathology and Laboratory Medicine, American University of Beirut Medical Center, Beirut, Lebanon

Correspondence to: Dr F R Jamali, Department of Surgery, American University of Beirut Medical Center, Beirut, Lebanon; fj03@aub.edu.lb

Competing interests: None.

Patient consent: Obtained.

Gut 2009;58:1176. doi:10.1136/gut.2008.173773 